\title{
O CONCEITO DE REMUNERAÇÃO E AS STOCK OPTIONS NO TST E NO CARF
}

\section{THE CONCEPT OF REMUNERATION AND THE STOCK OPTIONS IN TST AND CARF}

\section{Thiago de Carvalho e Silva e Silva ${ }^{1}$}

Resumo: Os conceitos de remuneração utilizado na análise das "stock options" pelo Tribunal Superior do Trabalho ("TST") e pelo Conselho Administrativo de Recursos Fiscais do Ministério da Fazenda (“CARF”) são absolutamente antagônicos, conforme se verifica em recentes decisões. Utilizando-se do método disposto pelo Constructivismo Lógico-Semântico, o objetivo deste trabalho é analisar a constituição da norma jurídica que veicula o conceito de remuneração no Ordenamento Jurídico e, pela comparação, confirmar dentre os conceitos utilizados pelo TST e pelo CARF qual seria mais próximo desta norma a partir de sua conformação decorrente do disposto no inciso XI do artigo $7^{\circ}$ da Constituição Federal e dos artigos 109 e 110 do Código Tributário Nacional.

Palavras Chave: direito do trabalho; direito tributário; conceito de remuneração; Constructivismo Lógico-semântico

Summary: The concept of remuneration used in the analysis of "stock options" by the Brazilian Superior Labor Court ('TST') and by the Brazilian Administrative Council of Tax Appeals of the Ministry of Finance ("CARF") are absolute opposites as evidenced in recent decisions. Using the method of Logic-Semantic Constructivism, the objective of this study is to analyze the composition of the legal rule that conveys the concept of remuneration in the Legal System and, by comparison, confirm among the concepts utilized by the TST and by the CARF which would be closer to the standard established in item XI of clause $7^{\circ}$ of the Brazilian Federal Constitution and clauses 109 and 110 of the National Tax Code.

Keywords: Labor Law; Tax Law; Conception of remuneration; Logic-Semantic Constructivism

\footnotetext{
${ }^{1}$ Doutorando e Mestre em Direito pela PUC-SP, na área de concentração Efetividade do Direito; Bacharel em Direito pela PUC-SP e em Administração de Empresas pelo Mackenzie; Presidente da Associação de Pós-Graduandos em Direito da PUC-SP (APGDireito/PUC-SP) no triênio 2015-2017. Representante discente da Pós-Graduação no Conselho da Faculdade de Direito da PUC-SP. Professor universitário e advogado com foco na área trabalhista.
} 


\section{Introdução}

A análise do conceito de remuneração no ordenamento jurídico é daquelas árduas tarefas que, além da dificuldade técnico-jurídica em si, impõe ao operador do direito interessado no tema aquele sentimento de que o conceito compreendido pelos formuladores de normas jurídicas, seja no âmbito do Tribunal Superior do Trabalho (“TST") seja no do Conselho Administrativo de Recursos Fiscais ("CARF") do Ministério da Fazenda, continuará imutável como se houvesse alguma verdade absoluta sobre esse tema. Ou seja, por mais pertinente metodologicamente que possa ser a abordagem escolhida - e esta é a única e singela pretensão do autor - talvez jamais seja alterado o conceito usado pelos respectivos operadores do direito.

Em outras palavras, dados os objetivos institucionais de cada um destes entes, é pouco provável a alteração do entendimento acerca do conceito de remuneração pelos formuladores de normas jurídicas (decisões judiciais trabalhistas ou administrativas fiscais), porque há elementos políticos que participam do ato de forjar tais formulações. Mas isso não desencoraja o autor em sua pretensão especificamente acadêmica que será externada a seguir, já que verdades absolutas não existem no plano da análise estritamente científica.

Sem se preocupar com a eventual incipiência pragmática da análise, a ideia central deste trabalho acadêmico é tão somente realizar uma apreciação comparativa entre o entendimento externado pelo TST e pelo CARF quando apreciam as rendas auferidas pelos empregados por força de planos de opção de compra de ações ("stock options").

Assim, usar-se-á qualificada metodologia, qual seja, o Constructivismo Lógico-Semântico. E, pela comparação, tentar-se-á confirmar dentre os conceitos utilizados pelo TST e pelo CARF qual seria o mais próximo desta norma a partir de sua conformação decorrente do disposto no inciso XI do artigo $7^{\circ}$ da Constituição Federal e dos artigos 109 e 110 do Código Tributário Nacional. 
O objetivo é lançar uma adicional e pequena "camada de linguagem" sobre o assunto em referência para a reflexão dos interessados, porventura podendo, com certa dose de otimismo, alcançar aqueles que produzem normas jurídicas decorrentes de decisões administrativas na ceara tributária para, quiçá, estimular novas reflexões.

Com tal justificativa, pretende-se neste artigo apreciar o conceito de remuneração inserido no ordenamento jurídico e, a partir deste, conferir qual conceito é utilizado na apreciação judicial de casos concretos pelo TST ao se analisar demandas de natureza trabalhista, assim como pelo CARF, ao se decidir recursos interpostos em face de decisões das Delegacias da Receita Federal do Brasil de Julgamento (DRJ). Em ambas situações, a análise do conceito de remuneração será feita exclusivamente quando se se depara com a realização de planos de opções de compra de ações para empregados de alto escalão de variadas sociedades empresárias.

Algumas decisões proferidas nos últimos 2 anos pelo CARF sobre o tema (Processo n. 15889.000245/2010-46 - julgado em 20/06/2013; Processo n. 10830.720565/2012-30 - julgado em 10/09/2014; Processo n. 10925.723207/2011-49 - julgado em 5/11/2014; Processo n. 16327.721267/2012-33 - julgado em 11/02/2015; etc.) têm aprofundado a divergência acerca do conceito de remuneração para fins de incidência das contribuições sociais previdenciárias, ora entendendo pela incidência ora não, ainda que as primeiras perfaçam a maioria e as segundas estejam estribadas em aspectos formais e não no conceito de remuneração propriamente dito.

Comparando-se algumas destas decisões com o conceito de remuneração/contraprestação utilizado pelo TST (Processo n. 85740-33.2009.5.03.0023 - julgado em 5/12/2010; Processo n. 20900-85.2007.5.15.0108 - julgado em 11/03/2015; Processo n. 201000-02.2008.5.15.0140 julgado em 11/02/2015, etc.) em demandas atinentes à integração dos valores auferidos por empregados em decorrência dos planos de opção de compra de ações para cálculo das demais verbas trabalhistas, verifica-se posição diametralmente oposta. 
Tais posições antagônicas são decorrentes da apreciação do conceito de opção de compra de ações e do conceito básico de direito do trabalho, qual seja, remuneração do trabalhador, além, é claro, da análise da abrangência do caráter de contraprestação dos valores auferidos a título do exercício de opção de compra de ações. Assim, a pretensão é submeter os dispositivos legais existentes sobre o tema aos testes científicos aplicados a partir do método decorrente do Constructivismo Lógico-Semântico, dada a utilidade ínsita à própria construção deste marco teórico, conforme acentua o professor PAULO DE BARROS CARVALHO, ao ministrar que

O Constructivimo Lógico-Semântico é, antes de tudo, um instrumento de trabalho, modelo para ajustar a precisão da forma à pureza e à nitidez do pensamento; meio e processo para a construção rigorosa do discurso, no que atende, em certa medida, a um dos requisitos do saber científico tradicional. (CARVALHO, 2014, p. 4)

\section{A constituição da norma jurídica que veicula o conceito de remuneração e o método do Constructivismo Lógico-Semântico}

Partindo-se da premissa de que a linguagem foi alçada ao patamar de pressuposto do próprio conhecimento relativo a qualquer objeto a partir da filosofia da linguagem (giro linguístico), cujo início é marcado pela obra Tractatus Lógico-philosophicus de Ludwig Wittgenstein, é conclusão inolvidável que o estudo da linguagem se tornou imprescindível para a compreensão do mundo e, por evidente, do direito de forma abrangente e seus conceitos básicos.

A importância desta abordagem para a apreciação pretendida neste estudo é facilmente verificável a partir das ricas explicações de AURORA TOMAZINI DE CARVALHO, ao aduzir que

É o homem quem dá significado às coisas quando constrói a relação entre uma palavra e aquilo que ela representa, associando-se a outras palavras que, juntas, formam sua definição. $O$ conhecimento nos dá acesso às definições. Não conhecemos as coisas em si, mas o significado das palavras dentro do contex to de uma língua e o significado já não depende da relação com a coisa, mas do vínculo com outras palavras. (TOMAZINI DE CARVALHO, 2013, p. 16) 
Ora, a construção da definição a partir da referência a outras palavras e nunca ao objeto em si, induz necessariamente ao entendimento da importância da linguagem para a apreensão do conhecimento, já que a essência das coisas se torna, portanto, algo intangível a partir dos limites metodológicos impostos pela filosofia da consciência (TOMAZINI DE CARVALHO, 2013, p. 17). É o chamado “cerco inapelável da linguagem”, dispostos pelo princípio da autorreferência do discurso, aspecto fundamental para a análise pretendida neste estudo.

Decorre, portanto, destas preliminares acepções a relevância da linguagem para a constituição do próprio direito, vez que o ato de interpretar o texto depende da forma com que o intérprete se relaciona com a linguagem escrita a partir de seu sistema de referência, erigindo deste processo as próprias normas jurídicas em sentido amplo. A evolução do entendimento acerca da norma jurídica fica perfeitamente indicada nas palavras de ROBSON MAIA LINS, ao apreciar o conceito de norma jurídica nas decisões do Supremo Tribunal Federal, ministrando em conclusão que

A declaração de inconstitucionalidade parcial sem redução de texto e a interpretação conforme a constituição são duas técnicas empregadas pelo STF nas ações de controle de constitucionalidade abstrato que denunciam a forte influência dos paradigmas da filosofia da linguagem nas decisões da Corte Maior. Nelas, não declara inconstitucionalidade (no caso da declaração de inconstitucionalidade parcial sem pronúncia de nulidade) ou constitucionalidade (quando a hipótese for de interpretação conforme a constituição) o suporte fáctico a partir do qual se constrói a norma jurídica (significação). É a própria significação que é declarada inconstitucional ou constitucional. (CARVALHO, 2014, p. 197)

Somente a partir da apreciação do direito sob o enfoque da filosofia da linguagem é que se tornou possível o estabelecimento deste novo entendimento de norma jurídica e, disso, a realização de julgamentos conforme os acima declinados. Torna-se claro que há utilidade na filosofia da linguagem tanto para a análise da norma jurídica posta em relação a sua constitucionalidade quanto, antes, para a constituição da própria norma jurídica em sentido amplo. 
Portanto, se, por um lado, a ampliação do conceito de norma jurídica é relevante e decorrente dos novos paradigmas impostos pelo giro linguístico, elevando ao foco principal "a atividade linguística do intérprete eleito pelo sistema como agente produtor de sentido por meio de atos de fala", como aduz ROBSON MAIA LINS, por outro lado fica evidente a relevância do sistema de referência deste intérprete, como bem aduz AURORA TOMAZINI DE CARVALHO, ao asseverar que

Cada pessoa dispõe de uma forma particular de conhecimento em conformidade com um sistema de referências adotado e condicionado por seus horizontes culturais. Em razão disso, não há que se falar em verdades absolutas, próprias de um objeto, porque o mesmo dado experimental comporta inúmeras interpretações. A verdade é uma característica da linguagem, determinada de acordo com o modelo adotado, pelas condições de espaço-tempo e também, pela vivência sócio-cultural de uma língua. É, portanto, sempre relativa. (TOMAZINI DE CARVALHO, 2013, p. 26)

De certa forma, já se pode assim justificar nos diferentes sistemas de referência dos intérpretes a existência de opostos entendimentos pelo TST e pelo CARF quando da apreciação do conceito de remuneração para se decidir acerca da incidência de contribuição previdenciária ou os reflexos das rendas auferidas com o exercício das opções de compra de ações nas demais verbas de natureza trabalhista.

A existência de sistemas de referência diferentes adotados pelos formadores das respectivas normas jurídicas pode induzir às conclusões diametralmente opostas, ou seja, ora os valores auferidos pelos empregados ou diretores são entendidos como parte da remuneração e, assim, base de cálculo da contribuição social prevista nos incisos I e III do artigo 28 da Lei n. 8.212/1991, ora são entendidos como estranhos ao conceito de remuneração e, assim, não utilizados para o cálculo das verbas de natureza trabalhista (férias, gratificação natalina, recolhimento do FGTS, aviso prévio, etc.). 
Ocorre que a formulação da norma jurídica em sentido estrito depende da linguagem abrangente do direito posto, não se permitindo subtrair apenas um trecho do texto para uma interpretação desejável sob o ponto de vista político de certa instituição responsável pela interpretação de normas de cunho previdenciário, como parece ocorrer, por vezes, nos julgamentos do CARF sobre esta matéria versada. A precisão científica na constituição da norma jurídica exige a apreciação abrangente dos textos de lei, enquanto partes constituintes do Ordenamento Jurídico. O professor PAULO DE BARROS CARVALHO ressaltou seu desejo em

(...) manifestar a convicção plena de que a realidade jurídica é constituída, em toda a sua extensão, em todos os seus momentos e manifestações, em todas as suas instâncias organizacionais, pela linguagem do direito posto, entrando nessa função configuradora tanto as normas gerais e abstratas e gerais e concretas, as quais decompostas, exibem a multiplicidade imensa dos enunciados jurídico-prescritivos. (CARVALHO, 2009, p. 162)

É interessante notar que esta "multiplicidade imensa dos enunciados jurídico-prescritivos" não implica de forma alguma a possibilidade de fragmentação do próprio sistema normativo, ou menos ainda a viabilidade de se extrair a norma jurídica de parcela isolada desta gama de enunciados. Pelo contrário. As normas jurídicas não estão presentes no ordenamento de forma isolada, sendo certo que estão postas em dado contexto e com relações particulares entre si. Recorrendo novamente aos ensinamentos do professor PAULO DE BARROS CARVALHO, devese destacar a lição:

Construir a norma aplicável é tomar os sentidos de enunciados prescritivos no contexto do sistema de que fazem parte. A norma é proposição prescritiva decorrente do todo que é o ordenamento jurídico. Enquanto corpo de linguagem vertido sobre o setor material das condutas intersubjetivas, o direito aparece como conjunto coordenado de normas, de tal modo que uma regra jurídica jamais se encontra isolada, monadicamente só: está sempre ligada a outras normas, integrando determinado sistema de direito positivo. (CARVALHO, 2009, p. 137/138) 
Dentre as várias lições que se extrai deste precioso conhecimento, a principal para este trabalho é aquela no sentido de que a formulação da norma jurídica em sentido estrito que estabelece a incidência da contribuição social sobre os rendimentos decorrentes do trabalho na hipótese de rendas auferidas pelo exercício de opção de compra de ações por empregados das empresas emissoras deste valor mobiliário depende da análise do conceito de remuneração previsto na legislação especial que regulamenta a matéria, qual seja, o do direito do trabalho, além da análise das normas que estabelecem o instituto da opção de compra de ações no direito posto e das decisões judiciais do TST que apreciam esta questão sob o ponto de vista protetivo do trabalhador, conforme adiante restará demonstrado.

Não é possível que a constituição da norma jurídica sobre o conceito de remuneração seja realizada exclusivamente sob a perspectiva do texto de lei previdenciário, como algo isolado dos demais trechos normativos.

\section{O conceito de remuneração no estabelecimento dos direitos trabalhistas e na legislação previdenciária}

A Constituição Federal de 5 de outubro de 1988 (CF), ao estabelecer os direitos sociais, veiculou em diversos incisos do artigo $7^{\circ}$ a palavra "salário" para garantir direitos básicos aos trabalhadores urbanos e rurais. No inciso IV estabeleceu a garantia ao "salário mínimo", indicando as necessidades básicas que esta verba deveria financeiramente suprir. O inciso $\mathrm{V}$ faz referência ao "piso salarial", já indicando a possibilidade das diversas categorias estabelecerem estes pisos através de negociação coletiva que considere a extensão e a complexidade do trabalho.

O relevante princípio da irredutibilidade salarial foi insculpido no inciso VI, com a indicação do "salário", assim como o inciso VII trouxe a garantia de "salário", nunca inferior ao mínimo, aos que auferem remuneração variável. 
O inciso XVII do mesmo artigo já citado veiculou o direito às férias anuais remuneradas, indicando o direito ao terço a mais do que o "salário normal". Por fim, apenas o décimo terceiro salário, historicamente denominado de gratificação natalina, foi vinculado à "remuneração integral" para indicar a sua forma de cálculo no inciso VIII do artigo $7^{\circ}$ da $\mathrm{CF}$.

Torna-se evidente, ab initio, que as principais garantias trabalhistas veiculadas na Constituição Federal fazem referência ao salário e não utilizam o conceito de remuneração, com exceção ao décimo terceiro salário, conforme acima indicado.

Ocorre, entretanto, que diversos direitos trabalhistas foram garantidos por texto infraconstitucional com referência à remuneração. Para tanto, a definição de remuneração de A.F. CESARINO JUNIOR é objetiva e clara, ao aduzir ser "o conjunto dos proventos que o empregado recebe, direta ou indiretamente, em virtude do trabalho prestado." (CESARINO JUNIOR, 1970, p. 136). Em nota de rodapé, o festejado doutrinador trabalhista, após indicar a vinculação da palavra "salarium" ao vocábulo "sal" e as vinculações de origem romana, indica que o vocábulo "remuneração" também possui origem latina, indicando o "remuneratio" do verbo "remuneror", que seria composto de "re", com a ideia de reciprocidade e "muneror", de recompensar. (CESARINO JUNIOR, 1970, p. 137).

A Consolidação das Leis do Trabalho, em seu artigo 457, traz a abrangência da remuneração nos seguintes termos:

Art. 457 - Compreendem-se na remuneração do empregado, para todos os efeitos legais, além do salário devido e pago diretamente pelo empregador, como contraprestação do serviço, as gorjetas que receber.

A partir desta indicação da esfera de abrangência da remuneração e da vinculação do salário como contraprestação do serviço prestado, a legislação que estabelece os direitos trabalhistas 
cujos reflexos se objetiva nas demandas trabalhistas julgadas pelo TST trazem as seguintes referências à remuneração.

As férias foram tratadas nos artigos 129 e 142 da CLT, com as seguintes redações:

Art. 129 - Todo empregado terá direito anualmente ao gozo de um período de férias, sem prejuízo da remuneração.

Art. 142 - O empregado perceberá, durante as férias, a remuneração que lhe for devida na data da sua concessão.

O décimo terceiro salário, denominado historicamente como gratificação natalina, está regido pela Lei n. 4.090/1962, cujo artigo $1^{\circ}$ e parágrafo primeiro estabelecem:

Art. $1^{\circ}$ - No mês de dezembro de cada ano, a todo empregado será paga, pelo empregador, uma gratificação salarial, independentemente da remuneração a que fizer jus.

$\S 1^{\circ}$ - A gratificação corresponderá a $1 / 12$ avos da remuneração devida em dezembro, por mês de serviço, do ano correspondente.

Da mesma forma, verifica-se a referência à remuneração na legislação que regula o Fundo de Garantia por Tempo de Serviço (FGTS), de forma que o artigo 15 da Lei. 8.036/1990, estabelece:

Art. 15. Para os fins previstos nesta Lei, todos os empregadores ficam obrigados a depositar, até o dia 7 (sete) de cada mês, em conta bancária vinculada, a importância correspondente a 8 (oito) por cento da remuneração paga ou devida, no mês anterior, a cada trabalhador, incluídas na remuneração as parcelas de que tratam os arts. 457 e 458 da CLT, a gratificação de Natal a que se refere a Lei no 4.090, de 13 de julho de 1962, com as modificações da Lei ${ }^{\circ} 4.749$, de 12 de agosto de 1965, e o valor da compensação pecuniária a ser paga no âmbito do Programa de Proteção ao Emprego - PPE.

É interessante notar que o $\S 6^{\circ}$ deste artigo 15 , ao desejar excluir do cálculo do FGTS alguns valores eventualmente recebidos pelo empregado, fez referência expressa ao $\S 9^{\circ}$ do artigo 28 
da Lei n. 8.212/1991, estabelecendo, assim, uma vinculação indissociável entre a base de cálculo da contribuição social discutida nesta análise e o FGTS, a saber:

$\S 6^{\circ}$ - Não se incluem na remuneração, para os fins desta Lei, as parcelas elencadas no $§ 9$ - do art. 28 da Lei no 8.212 , de 24 de julho de 1991.

O aviso prévio está previsto no artigo 477 da CLT e no artigo 487, § $1^{\circ}$, cujas redações são as seguintes:

Art. 477 - É assegurado a todo empregado, não existindo prazo estipulado para a terminação do respectivo contrato, e quando não haja ele dado motivo para cessação das relações de trabalho, o direto de haver do empregador uma indenização, paga na base da maior remuneração que tenha percebido na mesma empresa.

Art. 487 - Não havendo prazo estipulado, a parte que, sem justo motivo, quiser rescindir o contrato deverá avisar a outra da sua resolução com a antecedência mínima de:

I - oito dias, se o pagamento for efetuado por semana ou tempo inferior;

II - trinta dias aos que perceberem por quinzena ou mês, ou que tenham mais de 12 (doze) meses de serviço na empresa.

$\S 1^{\circ}$ - A falta do aviso prévio por parte do empregador dá ao empregado o direito aos salários correspondentes ao prazo do aviso, garantida sempre a integração desse período no seu tempo de serviço.

Percebe-se claramente que os direitos trabalhistas questionados nas demandas judiciais julgadas pelo TST, com exceção apenas ao aviso prévio, trazem a vinculação ao conceito de remuneração. Portanto, a apreciação pelo TST da inclusão ou não dos valores recebidos como rendas decorrentes do exercício da opção de compra de ações nos reflexos destas verbas trabalhistas necessariamente induz que as decisões do TST estejam efetivamente constituindo a norma jurídica que veicula o conceito de remuneração, a partir de seus referenciais de direito do trabalho.

Por outro lado, o artigo 28 e seu inciso I da Lei n. 8.212/1991, estabelecem que:

Art. 28. Entende-se por salário-de-contribuição: 
I - para o empregado e trabalhador avulso: a remuneração auferida em uma ou mais empresas, assim entendida a totalidade dos rendimentos pagos, devidos ou creditados a qualquer título, durante o mês, destinados a retribuir o trabalho, qualquer que seja a sua forma, inclusive as gorjetas, os ganhos habituais sob a forma de utilidades e os adiantamentos decorrentes de reajuste salarial, quer pelos serviços efetivamente prestados, quer pelo tempo à disposição do empregador ou tomador de serviços nos termos da lei ou do contrato ou, ainda, de convenção ou acordo coletivo de trabalho ou sentença normativa

A própria vinculação dos rendimentos pagos, devidos ou creditados a qualquer título ao fato de serem destinados a retribuir o trabalho já faz a questão do conceito desaguar no da remuneração estabelecida na legislação trabalhista e, claro, na norma jurídica constituída pelos intérpretes que julgam as demandas de natureza laboral, também pelas razões que serão a seguir aduzidas.

\section{O conceito de remuneração nos julgamentos realizados pelo TST}

O TST já firmou posicionamento desde 2010 na constituição da norma jurídica atinente ao conceito de remuneração, ao apreciar as rendas decorrentes do exercício da opção de compra de ações, asseverando que:

As "stock options", regra geral, são parcelas econômicas vinculadas ao risco empresarial e aos lucros e resultados do empreendimento. Nesta medida, melhor se enquadram na categoria não remuneratória da participação em lucros e resultados (art. 7, XI, da CF) do que no conceito, ainda que amplo, de salário ou remuneração. De par com isso, a circunstância de serem fortemente suportadas pelo próprio empregado, ainda que com preço diferenciado fornecido pela empresa, mais ainda afasta a novel figura da natureza salarial prevista na CLT e na Constituição. (TST - Processo n. 85740-33.2009.5.03.0023 - julgado em 15/10/2010).

Em decisões mais recentes, a exemplo da transcrita a seguir, o TST manteve este entendimento ao decidir que:

Em que pese a possibilidade da compra e venda de ações decorrer do contrato de trabalho, o trabalhador não possui garantia de obtenção de lucro, 
podendo este ocorrer ou não, por consequência das variações do mercado acionário, consubstanciando-se em vantagem eminentemente mercantil. Dessa forma, o referido direito não se encontra atrelado à força laboral, pois não possui natureza de contraprestação, não havendo se falar, assim, em natureza salarial. (TST - Processo n. 201000-02.2008.5.15.0140 - julgado em 11/2/2015).

É assente de dúvida que o direito do trabalho estabelece alguns princípios relevantes na defesa dos interesses do trabalhador, tais como o fundamental princípio protetor, que AMAURI MARCARO NASCIMENTO, fazendo referência ao conhecimento ofertado pelo uruguaio Américo Plá Rodrigues, assevera que:

Sustenta Plá Rodrigues que no direito do trabalho há um princípio maior, o protetor, diante da sua finalidade de origem, que é a proteção jurídica do trabalhador, compensadora da inferioridade em que se encontra no contrato de trabalho, pela sua posição econômica de dependência ao empregador e de subordinação às suas ordens de serviço. O direito do trabalho, sob essa perspectiva, é um conjunto de direitos conferidos ao trabalhador como meio de dar equilíbrio entre os sujeitos do contrato de trabalho, diante da natural desigualdade que os separa, e favorece uma das partes do vínculo jurídico, a patronal. (NASCIMENTO, 2013, p. 469)

Não restam dúvidas de que os intérpretes da legislação laboral estão sempre norteados pelo princípio protetor quando da constituição da norma jurídica em sentido estrito a ser aplicada aos julgamentos acerca do conceito de remuneração e a eventual inserção neste conceito daquelas rendas auferidas pelo exercício da opção de compra de ações. É claro que a constituição desta norma jurídica parte da premissa de que o empregado está em situação de relativa inferioridade, de sorte que a tendência seria, claro, a inclusão destas rendas de opção de compra de ações no conceito de remuneração para que os reflexos nas férias, décimo terceiro, FGTS e aviso prévio fossem garantidos judicialmente aos empregados.

Deve ser destacado o fato de que se trata de princípio informador do direito do trabalho, de relevância ímpar. Não se pode olvidar da lição de ROBERT ALEXY ao divisar os conceitos de regras e princípios, ao aduzir que: 
(...)a distinção entre regras e princípios forma o fundamento teóriconormativo, por um lado, da subsunção e, por outro, da ponderação. Regras são normas que ordenam algo definitivamente. Elas são mandamentos definitivos. A maioria das regras ordena algo para o caso que determinadas condições sejam cumpridas. Elas são, então, normas condicionadas. Mas também regras podem adquirir uma forma categórica. Um exemplo seria uma proibição de tortura absoluta. Decisivo é que então, quando uma regra vale e é aplicável, é ordenado definitivamente fazer rigorosamente aquilo que ela pede. Se isso é feito, a regra está cumprida; se isso não é feito, a regra não está cumprida. Regras são, por isso, normas que sempre somente ou podem ser cumpridas ou não-cumpridas. Pelo contrário, princípios são normas que ordenam que algo seja realizado em uma medida tão alta quanto possível relativamente às possibilidades fáticas e jurídicas. Princípios são, por conseguinte, mandamentos de otimização. Como tais, eles são caracterizados pelo fato de eles poderem ser cumpridos em graus diferentes e de a medida ordenada de seu cumprimento depender não só das possibilidades fáticas, mas também das jurídicas. As possibilidades jurídicas são, além de pelas regras, essencialmente determinadas por princípios em sentido contrário. (ALEXY, 2008, p. 131/132)

O fato de não considerarem estes rendimentos no conceito de remuneração, a partir da ponderação, também, de diversos outros princípios informadores do direito do trabalho, especialmente aqueles decorrentes do princípio protetor, como o in dubio pro operario, a prevalência da norma favorável ao trabalhador e a preservação da condição mais benéfica, é relevante para a constituição da norma jurídica em sentido estrito que trata da remuneração para fins previdenciários quando se está apreciando a mesma renda em apreço, qual seja, aquela decorrentes do exercício das opções de compra de ações.

\section{O conceito de remuneração nos julgamentos realizados pelo CARF}

Por seu turno, o CARF tem apreciado o exercício de opções de compra de ações realizado por empregados das empresas emissoras destes valores mobiliários sob o ponto de vista previdenciário, a fim de julgar recursos interpostos em face de decisões proferidas pelas diversas Delegacias de Julgamento da Receita Federal do Brasil. 
Neste ponto, é importante destacar que em alguns dos julgados apreciados o interesse objetivado pelas empresas que estabelecem os planos de opção de compra de ações é bem definido, inclusive com a indicação histórica do instituto desde sua criação nos anos 1960 nos Estados Unidos da América. É evidente o reconhecimento de que o objetivo principal é aproximar os interesses do empregado ao da empresa, o que se assevera, por exemplo, da seguinte forma:

A estratégia adotada pelas organizações americanas, portanto, foi, à toda evidência, tornar parcela dos empregados em proprietários da empresa, o que certamente surte efeito psicológico significativo no comprometimento pela realização dos objetivos sociais da companhia.

\section{$(\ldots)$}

Não se pode negar que a incorporação dessa estratégia também rende bons resultados na produtividade dos então empregados que ao exercerem a opção de compra de ações passam a ser acionistas da empresa. E, com razão, já que esse novel acionista não mais fica mais adstrito a mera relação então vigente, qual seja, a de prestar serviços mediante remuneração, mas a de comungar com a sociedade em interesses que lhes são próprios e naturais, com vistas a obter lucro e, assim, auferir dividendos. (CARF Processo n. 15889-000245/2010-46 - Acórdão n. 2301-003.597 - julgado em 20/06/2013)

Vale dizer que o trecho acima declinado foi extraído do voto do relator do recurso apreciado perante o CARF, tendo sido vencido pela maioria. De qualquer forma, este trecho demonstra com clareza qual é o objetivo principal do estabelecimento de um plano de opção de compra de ações oferecido aos empregados ou diretores. E é evidente que este objetivo se alinha perfeitamente com o disposto no artigo $7^{\circ}$, inciso XI da CF, que aduz:

Art. $7^{\circ}$ - São direitos dos trabalhadores urbanos e rurais, além de outros que visem à melhoria de sua condição social:

XI - participação nos lucros, ou resultados, desvinculada da remuneração, e, excepcionalmente, participação na gestão da empresa, conforme definido em lei; 
Não por outro motivo o TST aproxima a figura da renda auferida com o exercício da opção de compra de ações à da Participação nos Lucros e Resultados, conforme Acórdão parcialmente transcrito acima e outros indicados no início deste trabalho.

De qualquer forma, o CARF tem rejeitado os recursos dos contribuintes e mantido a exação previdenciária, afastando o plano de opção de compra de ações de sua natureza eminentemente mercantil, na hipótese, por evidente, de efetiva estruturação de clássico plano de opção de compra de ações, ou seja, a opção sem o objetivo de simular pagamento de salário através do pagamento pela empresa apenas da diferença positiva entre o valor de mercado atingido no momento do exercício da opção e o valor de mercado (ou estipulado de forma irrisória) no momento inicial do estabelecimento do plano. Este último caso é conhecido como "phantom stock option” e não é a hipótese abordada neste trabalho.

Os principais aspectos indicados nos julgamentos contrários aos contribuintes são: (1) inexistência de pagamento pelo empregado ou diretor no ato do estabelecimento do plano de opção de compra de ações, ou seja, o empregado não paga pela compra da opção, ou o valor inicial da opção é irrisório comparado ao potencial de ganho a partir do valor de mercado das ações na data do estabelecimento do plano; e (2) o valor futuro da ação é menor que o valor da ação no mercado na data do estabelecimento do plano, isto é, a projeção é de que o valor das ações poderá cair no prazo de carência estabelecido até a data do exercício da opção.

Ora, primeiramente, é fundamental perceber que o dispositivo que estabelece a possibilidade de constituição de plano de opção de compra de ações por diretores e empregados é o artigo 168, parágrafo 3 da Lei n. 6.404/1976, que prevê:

Art. 168 - O estatuto pode conter autorização para aumento do capital social independentemente de reforma estatutária. 
3 - O estatuto pode prever que a companhia, dentro do limite de capital autorizado, e de acordo com plano aprovado pela assembléia geral, outorgue opção de compra de ações a seus administradores ou empregados, ou a pessoas naturais que prestem serviços à companhia ou a sociedade sob seu controle.

A partir deste regramento isolado, DANIEL GUSTAVO PEIXOTO ORSINI MARCONDES apresenta o seguinte conceito:

As stock options são, de maneira bastante simplificada, opções de compra das ações da própria sociedade. Uma opção de compra dá o direito, a seu titular, de adquirir uma ação de alguém (o emissor ou lançador da opção), por um determinado preço (chamado preço de exercício). As condições para que os executivos adquiram essas opções podem variar conforme o plano. Por exemplo, alguns planos exigem que o executivo preste serviço para a sociedade durante determinado tempo (vesting period). Outros planos, além de um prazo de permanência mínimo, podem exigir que determinada meta seja atingida (por exemplo, incremento nas vendas). Por fim, também existem os planos que concedem tais opções desde o início, sendo esses os mais simples. (MARCONDES, s.d., p. 25)

Com este conceito e detalhamento, na sequência, o referido doutrinar indica que as opções de compra de ações são valores mobiliários porque possuem as ações como ativo subjacente, na hipótese do plano se referir a ações de Sociedades Anônimas, que são valores mobiliários por definição. Entretanto, destaca também o doutrinador que a normativa da Comissão de Valores Mobiliários - CVM que regulamentava a matéria no momento do texto publicado (Instrução Normativa n. 400/2003) não exigia que a CVM realizasse prévia apreciação da distribuição da opção na hipótese disso ocorrer para pessoas com prévia relação comercial, creditícia, societária ou trabalhista com a emissora. Em que pese as diversas alterações realizadas nesta normativa, a exceção acima indicada ainda existe através do disposto $\S 1^{\circ}$ do artigo $3^{\circ}$ da mesma Instrução Normativa. 
Portanto, a aprovação de plano de opção de compra de ações para diretores e empregados da empresa não depende da prévia aprovação da CVM, não estando submetido às normativas de referida Comissão.

Resta claro, portanto, que a legislação existente sobre o assunto não preceitua valores mínimos para a oferta das opções de compra das ações, ou seja, não há norma obrigando que o valor da compra da opção seja vinculado de alguma forma ao valor de mercado da própria ação na data de estabelecimento do plano. Aliás, não é demais recordar que a aquisição da opção não se confunde com a aquisição da própria ação, de sorte que estabelecer o valor da compra da opção com referencial ao valor da ação não faria sentido. Fosse assim, então, por evidente, o empregado deveria preferir adquirir a própria ação e não pagar apenas por um direito potestativo, qual seja, exercer a opção após o prazo de carência estabelecido.

Portanto, o primeiro requisito indicado como caracterizador do rendimento do exercício da opção de compra de ações como de natureza remuneratória não seria juridicamente sustentável, tanto pela própria ausência de norma impondo o estabelecimento de valor mínimo para a aquisição da opção quanto pela inviabilidade lógica de se exigir pagamento de valor referenciado ao valor da própria ação.

É equivocado o entendimento de que não pagar pela opção de compra de ações no momento do estabelecimento do plano seria não assumir riscos inerentes às operações mercantis desta natureza. Ora, o objetivo do empregado ou diretor, claro, é auferir ganho de capital decorrente da valorização da ação entre o valor estipulado no ato do estabelecimento do plano e o valor futuro da ação no mercado, o que motivaria o exercício da opção, ou seja, o pagamento do valor preestabelecido da ação para eventual alienação subsequente a ponto de auferir ganho de capital. 
Nesta hipótese, ainda que o empregado ou diretor nada tenha pago pela opção de compra, há o risco de não ter havido valorização da ação, ou até mesmo desvalorização para patamar inferior ao estabelecido no ato do estabelecimento do plano, sendo certo que, nesta situação, o empregado ou diretor não auferirá qualquer vantagem econômica. Ter sido atraído pela oferta de opção de compra de ações, ter permanecido trabalhando para a empresa durante o prazo de carência para o exercício e não auferir vantagem econômica ao final é, a toda evidência, a assunção de um verdadeiro prejuízo derivado do risco assumido.

O segundo requisito, por outro lado, efetivamente caracterizaria o desvirtuamento da figura da opção de compra de ações, verdadeira simulação, a justificar a incidência da contribuição previdenciária. O estabelecimento de valor futuro da ação em patamar inferior ao valor presente no ato de estabelecimento do plano seria contrário ao próprio objetivo primordial do plano, qual seja, motivar a permanência do empregado ou diretor na empresa pelo período de carência e, simultaneamente, aproximar os objetivos do empregado e da empresa. Isso porque o ganho decorrente do exercício da opção não mais decorreria da valorização das ações a partir, também, do empenho dos empregados e diretores. Nesta hipótese, o único objetivo seria remunerar, com grandes chances disso ocorrer, os empregados e diretores através de instituto que não se presta a tal desiderato.

Por fim, há um posicionamento em alguns julgamentos do CARF, conforme transcrito abaixo, que parece conjugar a discussão sobre o conceito de remuneração com a relativa ao vínculo de emprego, o que faz nos seguintes termos:

Neste caso, para este singelo julgador, em havendo uma condicionante de manutenção de vínculo empregatício, subordinação, dependência e sobretudo a determinante de risco tão somente ao contratado, não se pode dizer que é uma 'Stock Options ou Employee Stock Options (EOS)', porque ela perde a característica mercantil cível, passando a ser puramente relação de vínculo de trabalho, incidindo contribuição previdenciária. 
De forma que para se distinguir a relação aqui existente de emprego de uma possível mercantil cível, como quer a Recorrente, mister que se analise mais que a suficiência do critério da participação integrativa do trabalho na atividade normal do tomador de serviço, sinal distintivo da nãoeventualidade. Mas, sobretudo, necessário analise percuciente da intensidade da subordinação em seu conceito tradicional, tal como questionar sobre a organização própria do 'empreendedor/trabalhador' e, sobretudo, a ingerência não acentuada do tomador na atividade do prestador do trabalho.

Na presente parlenda há traços marcantes da subordinação, dependência e controle, que determinam a relação de contrato de trabalho ao simples fato de a Recorrente estabelecer no contrato que a opção de compra somente poderá ser exercida pelo empregado/beneficiário enquanto este prestar serviços a ela e ou a Companhia. (CARF - Processo n. 10830.720565/201230 - julgado em 10/09/2014)

Ora, a conclusão inolvidável da aplicação deste entendimento seria no sentido de que jamais seria possível o estabelecimento de plano de opção de compra de ações para empregados da empresa sem que tais pagamentos se configurassem como remuneração, o que parece não ter qualquer relação ou enunciado normativo neste sentido. É assente de dúvidas que pode haver pagamento de valores para empregado que não seja caracterizado como remuneração, afastando a incidência de contribuição previdenciária. A conjugação dos requisitos para a caracterização do vínculo de emprego com o conceito de remuneração, salvo melhor juízo, não possui qualquer justificativa no ordenamento jurídico.

Por estas razões, excetuada a hipótese de plano de opção de compra de ações com a existência do pressuposto indicado acima como item (2), todos os demais casos deveriam respeitar a norma jurídica estabelecida a partir dos enunciados de direito do trabalho e das decisões judiciais proferidas pelo TST, além da limitação imposta pelos artigos 109 e 110 do Código Tributário Nacional, conforme adiante demonstrado.

\section{O sistema de referência dos intérpretes e os artigos 109 e 110 do Código Tributário}

\section{Nacional}


Já foi destacado acima que o sistema de referência é relevante porque as apreciações de todo e qualquer enunciado dependem, para sua interpretação, daquelas condições próprias do sujeito que se encontra no exercício da hermenêutica. É algo individual e particular. A própria afirmação de que algo é verdadeiro depende do modelo segundo o qual a proposição está sendo apreciada, conforme ensina PAULO DE BARROS CARVALHO (2009, P. 26).

Este aspecto relativo chega ao ponto de que o próprio sistema de referência é, também, variável, a depender dos pressupostos adotados para se caracterizar algo como sistema de referência. Segundo AURORA TOMAZINI DE CARVALHO aduz

O próprio sistema referencial, dentro do qual são processadas e verificadas as informações tidas por verdadeiras, é um conjunto de crenças, ou seja, de outras proposições tomadas como verdadeiras. Acolhemos certas crenças e as utilizamos como ponto de partida para o desenvolvimento de novas proposições que, por consonância com aquelas são tomadas como verdadeiras. Uma crença, assim, se sustenta sempre em outra, caracterizando-se as proposições verdadeiras como interpretações que coincidem com outras interpretações prévias. (TOMAZINI DE CARVALHO, 2013, P. 34)

Ocorre, entretanto, que esta relatividade e incerteza acerca do sistema de referência do intérprete, por exemplo, não quer dizer instabilidade do próprio sistema normativo, tampouco que não existam certos limites, no próprio sistema, para a realização do exercício de se apreciar o conjunto normativo e extrair a norma jurídica em sentido estrito. A própria apreciação do conjunto normativo sob uma perspectiva científica já exige, por si só, o respeito aos vocábulos utilizados (vêse claramente a importância da semiótica neste aspecto) na seleção que se pretende ser precisa pelo legislação na escolha dos termos utilizados.

Logo, não se pode olvidar, portanto, que os sentidos dos vocábulos utilizados no texto devem ser respeitados para se manter a higidez do próprio Ordenamento Jurídico em sua 
perspectiva científica, conforme já decidiu, inclusive, o Supremo Tribunal Federal, em voto da lavra do Ministro Marco Aurélio, que aduziu:

O conteúdo político de uma Constituição não é conducente ao desprezo do sentido vernacular das palavras, muito menos ao do técnico, considerados institutos consagrados pelo direito. Toda ciência pressupõe a adoção de escorreita linguagem, possuindo os institutos, as expressões e os vocábulos que a revelam conceitos estabelecidos com a passagem do tempo, quer por força de estudos acadêmicos, quer, no caso do direito, pela atuação dos Pretórios.

Já se disse que as questões de nome são de grande importância, porque, elegendo um nome ao invés do outro, torna-se rigorosa e não suscetível de mal-entendido uma determinada linguagem. A purificação de linguagem é uma parte essencial da pesquisa científica, sem a qual nenhuma pesquisa poderá dizer-se científica. (STF - RE 166.772-9-RS, Pleno, rel. Ministro Marco Aurélio, DJ 16.12.1994)

Portanto, nesta esteira, o conteúdo técnico do vocábulo remuneração deve ser respeitado, a partir da construção da norma jurídica veiculada nos textos de direito do trabalho e pelo intérprete nos julgamentos proferidos pelo TST, conforme acima declinado. Não se negligencia que esta construção da norma jurídica é algo dinâmico, que se adapta aos conflitos e contexto social, conforme bem alinhavou EROS ROBERTO GRAU, ao aduzir que

(...) a aplicação do direito - e este ato supõe interpretação - não é mera dedução dele, mas, sim, processo de contínua adaptação de suas normas à realidade e seus conflitos. Da mesma forma, a ordem jurídica, no seu evolver em coerência com as necessidades reais, embora haja de respeitar a Constituição, não se resume a uma mera dedução dela. A Constituição é um dinamismo. É do presente, na vida real, que se tomam as forças que conferem vida ao direito - e à Constituição. Assim, o significado válido dos princípios é variável no tempo e no espaço, histórica e culturalmente." (GRAU, 2010, p. 166)

Além disso, há, inclusive, enunciados próprios na seara do direito tributário que preceituam esta observância dos demais dispositivos do direito do trabalho na conformação da 
norma jurídica que veicula o conceito de remuneração, conforme disposto nos artigos 109 e 110 do Código Tributário Nacional, que asseveram:

Art. 109. Os princípios gerais de direito privado utilizam-se para pesquisa da definição, do conteúdo e do alcance de seus institutos, conceitos e formas, mas não para definição dos respectivos efeitos tributários.

Art. 110. A lei tributária não pode alterar a definição, o conteúdo e o alcance de institutos, conceitos e formas de direito privado, utilizados, expressa ou implicitamente, pela Constituição Federal, pelas Constituições dos Estados, ou pelas Leis Orgânicas do Distrito Federal ou dos Municípios, para definir ou limitar competências tributárias.

Os dispositivos acima transcritos, cuja vinculação mútua é evidente, indicam que a opção pelo legislador brasileiro foi no sentido de que a interpretação econômica pode ser realizada, mas de modo excepcional, já que a forma estabelecida pelo direito privado deve ser respeitada no tocante à definição, ao conteúdo e alcance dos institutos, conforme assevera ALIOMAR BALEEIRO, ao dizer que

O CTN se apresenta tímido quanto à interpretação econômica: insinua-a, mas não a erige em princípio básico, proclamando, pelo contrário, o primado do Direito Privado quanto à definição, ao conteúdo e alcance dos institutos, conceitos e formas deste ramo jurídico quando utilizado pela Constituição Federal, pelas dos Estados ou pelas Leis Orgânicas do DF e dos Municípios. (BALEEIRO, 1981, p. 396)

Nestes termos, torna-se sustentável que a utilização das formas jurídicas estabelecidas no direito privado deve estar presente no exercício da constituição da norma jurídica que configura a incidência da contribuição social em matéria de rendimentos decorrentes do exercício da opção de compra de ações, especificamente no tocante ao conceito de remuneração trazido do direito do trabalho e apreciado pelos Tribunais Trabalhistas.

A exceção que se justificaria, claro, para a preponderância da interpretação econômica com o abandono da forma de direito privado seria as hipóteses de abuso de forma ou simulação, cujas hipóteses não estão sendo aqui tratadas porque se encerrariam na situação dos chamados "phantom 
stock options", conforme acima já mencionada. As situações tratadas neste trabalho são das clássicas stock options em favor de empregados e que devem, na apreciação da incidência previdenciária, respeitar as formas jurídicas da própria estruturação da operação mercantil dos planos de opção de compra de ações e ao conceito de direito do trabalho no tocante à remuneração.

Por derradeiro, não se poderia olvidar das limitações impostas, ou melhor dizendo, dos vetores impositivos de condutas escolhidas pelo legislador decorrentes dos princípios, que já denotam valores selecionados pelos legisladores como relevantes para o convívio social. A importância dos valores na formação da própria estrutura lógico-formal da norma foi indicada por PAULO DE BARROS CARVALHO, que ministrou:

Outro tanto se diga no que atina ao modo de regular a conduta entre os sujeitos postos em relação deôntica. As possibilidades são três, e somente três: obrigatória, permitida ou proibida. Os modais "obrigatório" e "permitido" trazem a marca de um valor positivo, porque relevam que a sociedade aprova o comportamento prescrito, ou mesmo o tem por necessário para o convívio social. Caso o functor escolhido seja o "proibido", fica nítida a desaprovação social da conduta, manifestando-se inequívoco valor negativo. Vê-se que o valor está na raiz mesma do deverser, isto é, na sua configuração lógico-formal. (CARVALHO, 2009, p. $174 / 175)$

Nesta esteira, já se indicou acima a importância no aspecto constitucional da integração entre os entes econômicos, em sua configuração empresarial, e os empregados atuantes nestas mesmas empresas, como um próprio valor insculpido na Constituição Federal, de harmonização entre o capital e o trabalho. A participação dos empregados na gestão da empresa, assim como a sua participação nos lucros é atividades estimuladas pelo legislador constitucional.

O estabelecimento de planos de opção de compra de ações é um importante meio para se atingir este objetivo relevante, de forma que a utilização do conceito de remuneração estabelecido enquanto norma jurídica pela interpretação dos julgadores que compõe as turmas do TST é medida que se impõe. 


\section{Conclusão}

Os conceitos de remuneração utilizado na análise das "stock options" pelo Tribunal Superior do Trabalho e pelo Conselho Administrativo de Recursos Fiscais do Ministério da Fazenda são absolutamente antagônicos, como mencionado inicialmente neste trabalho. Ocorre que a constituição da norma jurídica que veicula o conceito de remuneração no Ordenamento Jurídico deve respeitar os julgamentos realizados pelo TST, tanto pela conformação decorrente dos princípios que informam o Direito do Trabalho, quanto pela conformação decorrente do disposto no inciso XI do artigo $7^{\circ}$ da Constituição Federal e dos artigos 109 e 110 do Código Tributário Nacional.

Assim, utilizando-se do conceito de remuneração veiculado pela norma jurídica constituída pelos julgamentos do TST, não deveria haver incidência das contribuições sociais previstas nos incisos I e III do artigo 28 da Lei n. 8.212/1991 em relação às rendas auferidas pelos empregados quando do exercício de opção de compra de ações.

\section{Referências}

ALEXY, R., 2008. Constitucionalismo discursivo. $2^{\text {a }}$ ed. Porto Alegre: Livraria do Advogado.

BALEEIRO, A., 1981. Direito tributário brasileiro. 10ª ed. Rio de Janeiro: Forense.

CARVALHO, P. d. B. [. a., 2014. Constructivismo Lógico-Semântico. São Paulo: Noeses.

CARVALHO, P. d. B., 2009. Direito tributário, linguagem e método. $3^{\mathrm{a}}$ ed. São Paulo: Noeses.

CESARINO JUNIOR, A., 1970. Direito social brasileiro. 6ª ed. São Paulo: Saraiva.

GRAU, E. R., 2010. A ordem econômica na Constituição de 1988. 14ª ed. São Paulo: Malheiros.

MARCONDES, D. P. O., s.d. Instituto Brasileiro de Direito Tributário - Direito Tributário Atual $n$. 28. São Paulo: Dialética.

NASCIMENTO, A. M., 2013. Curso de Direito do Trabalho. $28^{a}$ ed. São Paulo: Saraiva.

TOMAZINI DE CARVALHO, A., 2013. Curso de Teoria Geral do Direito. $3^{\text {a }}$ Ed. ed. São Paulo: Noeses. 